\title{
Computed tomography angiography in the diagnosis of arteriovenous malformations
}

\author{
Zulejha Merhemic ${ }^{*}$, Lidija Lincender², Emir Guso ${ }^{3}$ Emina Bicakcic ${ }^{4}$ Edin Avdagic ${ }^{5}$, \\ Majda M. Thurnher ${ }^{6}$
}

1Sunce-Agram Polyclinic, Sarajevo, Bosnia and Herzegovina, ${ }^{2}$ Academy of Science and Arts of Bosnia and Herzegovina, Sarajevo, Bosnia and Herzegovina, ${ }^{3}$ General Hospital, Sarajevo, Bosnia and Herzegovina, ${ }^{4}$ University Clinical Center of Sarajevo, Sarajevo, Bosnia and Herzegovina, ${ }^{5} \mathrm{Al}$-Tawil Polyclinic, Sarajevo, Bosnia and Herzegovina, ${ }^{6}$ Department of Biomedical Imaging and Image-guided therapy, Medical University, Vienna, Austria

\begin{abstract}
Introduction: The most common cause of intracranial bleeding in younger patients and children is vascular anomalies. Digital subtractions angiography presents a gold standard in diagnostics of aneurysms and vascular malformations. Our aim is to present our experience in using computed tomography angiography (CTA) in diagnosing arteriovenous malformations.

Methods: We included 150 patients with acute non-traumatic intracranial hemorrhage diagnosed by non-contrast CT examination, after which they were subjected to CTA of the cerebral vessels and then underwent maximum intense projection and volume rendering reconstruction.
\end{abstract}

Results: Out of 150 patients with non-traumatic intracranial hemorrhage, in 121 (81\%) patients, a diagnosis of aneurysm was rendered, while in $8(5 \%)$ patients arteriovenous malformation was found. In $29(14 \%)$ patients cause of bleeding was not identified. Patients with arteriovenous malformations were age 17-77 years, with the mean age of 42.75 years. $5(62.5 \%)$ of them were female patients and $3(37.5 \%)$ were male patients.

Conclusion: Spontaneous non-traumatic intracranial hemorrhage is a significant cause of morbidity and mortality. CTA is sufficiently specific and sensitive in diagnosis of arteriovenous malformations in our experience.

Key words: Computed tomography; angiography; arteriovenous malformations; digital subtraction angiography

\footnotetext{
*Corresponding author:Zulejha Merhemić, Kosevo 5, 71000 Sarajevo, Bosnia and Herzegovina.

E-mail: merhemic.zulejha@gmail.com
}

Submitted: 22 September 2017/Accepted: 1 December 2017

DOI: https://doi.org/10.17532/jhsci.2017.521

\section{INTRODUCTION}

Intracranial hemorrhage is one of the most frequent causes of acute neurological deficiency, and it is an indication for urgent diagnostics. Trauma is frequent cause of intracranial hemorrhage. Radiological findings have direct influence on therapy and prevention of complications (1). The most common cause of intracranial bleeding in younger patients and children is vascular anomalies (2). Intracranial vascular malformations in 
brain are found in $0.14-4 \%$ of general population (3), with the incidence of 1.84 per 100,000 people/year, and about 1.22 within symptomatic patients (4).

Vascular malformations are abnormal clusters of blood vessels that occur during fetal development. The term vascular malformation is general and includes congenital vascular anomalies of veins, lymphatic vessels, or both veins and lymphatic vessels, or both arteries and veins. The exact cause of these malformations remains unknown. Both males and females are equally affected. Arteriovenous malformations (AVMs) of the brain are abnormal focal conglomerations of dilated blood vessels, both arteries and veins, within brain parenchyma, in which a loss of normal vascular organization at the subarteriolar level and lack of a capillary bed result in abnormal arteriovenous shunting (5). These lesions are divided into the classic AVM and arteriovenous fistulas.

AVM results from an abnormal connection between the arteries that normally supply the brain parenchyma and the veins that drain-specific region of the brain. Usually, AVM is presented with an enlarged feeding artery, a nidus formed of a large number of AV shunts and dysplastic vessels, and enlarged draining vein. AVMs can occur anywhere in central nervous system, but majority are supratentorial (ST). $98 \%$ of these lesions are solitary. If multiple AVMs occurred, it is a need to consider syndromes such as cerebrofacial arteriovenous metameric syndrome or hereditary hemorrhagic telangiectasia (6).

Digital subtractions angiography (DSA) presents a gold standard in diagnostics of aneurysms and vascular malformations (7), but it is not the first diagnostic procedure in diagnosis of cause intracranial bleeding. Computed tomography angiography (CTA) and magnetic resonance angiography (MRA) are non-invasive methods which were developed in recent years.

Incidence of AVM in general population is $0.04-$ $0.52 \%$ for solitary AVM. Multiple AVMs are rare, $2 \%$ of all AVMs, and most usual in Osler-Weber-Rendu disease or in Wyburn-Mason syndrome $(0.003 \%$ of all cases) (8). In 85\% AVM is founded ST, and 2:1 or 3:1 cases are found on surface of brain (9). The most often manifestation is intracranial bleeding in between 20 and 40 years old patients (10). $25 \%$ of all
AVMs are manifested with bleeding in first 15 years of life. In $1 \%$ of all cases, vascular insult in brain can be the first manifestation of an AVM, and epilepsy is present in $25 \%$ of all cases (11).

According to some authors, risk from bleeding is bigger for small AVMs, and it is the same within all people who have AVM presented (12).

In patients who had bleeding as a symptom, risk for new bleeding in the $1^{\text {st }}$ year is between $6 \%$ and $17 \%$, and after 3 years is dropping on baseline $(13,14)$. After the second bleeding from AVM, risk for recurrent bleeding in the next year increases to 25\% (15). As a diagnostic method, CTA and MRA give a good preview about position and size of AVM, but they are not sufficiently precise to show subtle feeders. CT and MRI native series can help to set diagnosis of AVM. DSA is still a method of choice in diagnosis and treatment plan for AVMs.

Our aim is to show our experience in using the CTA for diagnosis of AVM.

\section{METHODS}

The prospective research included 150 patients with acute non-traumatic intracranial hemorrhage. $95(63 \%)$ of them were female and $55(37 \%)$ were men. The average age was 52.79 (range 15-78 years). All patients immediately after having diagnosed intracranial hemorrhage by non-contrast CT examination, underwent CT angiography of the cerebral vessels, and after underwent intense maximum projection (MIP) and volume rendering (VR) reconstruction.

Patients with positive findings by one and/or other method are sent directly to surgery or to DSA and then, if the finding is confirmed, they are sent to surgery or emergency treatment. All patients with the diagnosis of intracranial hemorrhage and CT angiography findings were normal, underwent DSA.

CT angiography was performed on the multilayer and multidetector apparatus from KCUS: 4-Layer Volume Zoom Siemens, Erlangen, Germany, and 64-layer Light Speed GE, USA.

Conventional angiography was performed at the Department of Radiology, KCUS, on the apparatus Axiom Artis, Siemens, Erlangen, Germany, by the Seldinger method. 


\section{RESULTS}

Of the 150 patients with non-traumatic intracranial hemorrhage, in 121 (81\%) patients were diagnosed aneurysm, and in $8(5 \%)$ patients were AVM, whereas in $29(14 \%)$ patients, we did not found the cause of bleeding.

Patients that had been diagnosed AVM, were the range age of 17-77 years, with the mean age of 42.75 years. $5(62.5 \%)$ of them were female patients and $3(37.5 \%)$ male patients (Table 1 and Figure 1). Three were found in the posterior cranial fossa infratentorial (IT) and five ST.

Volume of AVM is the same in the DSA, MIP, and VR reconstruction of CT angiography. The presence of an aneurysm within the AVM nidus was diagnosed in one patient. Of the 14 arteries which supply blood to AVM, CT angiography diagnosed 7 MIP and 8 VR reconstruction of CTA (Table 2).

There was a significant difference between MIP and DSA methods in assessing the number of arterial blood vessels that supply AVM and venous drainage $(p=0.039)$, while the difference between the findings of VR and DSA was not significant $(p=0.066)$.

\section{DISCUSSION}

Spontaneous non-traumatic intracranial hemorrhage is a significant cause of morbidity and mortality in the world. Intracranial hemorrhage is considered as medical emergency. Prompt diagnosis and treatment are of great importance at patients with non-traumatic intracranial hemorrhage as it comes to a deterioration of the situation in the $1^{\text {st }}$ hours after the occurrence of bleeding.

According to Rinkel et al. (16) at 15-20\% of patients with non-traumatic intracranial hemorrhage, the presence of aneurysm or vascular malformation was not proved completely correlating with our findings of $14 \%$ of patients with no aneurysm or vascular anomalies. Ideal examination for detecting the cause of non-traumatic intracranial hemorrhage, aneurysm, or vascular malformation should not only be the method which is non-invasive, easily performable, always accessible, and associated with minimal complications but also the method that should diagnose the aneurysm or vascular malformation with high accuracy for a successful surgical or endovascular treatment.

AVMs are congenital changes which are found according to Osborn et al. (18) in $85 \%$ of cases in the ST space. In our study of 150 patients with intracranial hemorrhage, we diagnosed eight arteriovenous malformations. Three AVMs were diagnosed in the posterior cranial fossa, which is not consistent with the literature because AVMs are much rarer in IT space.

Only in the case of hereditary diseases, we can find more than one AVM in one patient, while in the majority there is only one AVM, as in our study. Intracranial hemorrhage is the most common symptom which presents the AVM. Smaller AVM bleed more often, which can be seen in this small series where eight AVM, six of which were minor bled, although larger AVMs can bleed, but less frequently.

At AVM hemorrhage occurs between 20 and 40 years (25\% at age 15$)$ according to Perry (17), whereas

TABLE 1. Characteristics of AMV diagnosed in patients. Correlation between CTA MIP and VR reconstructions and DSA=

\begin{tabular}{|c|c|c|c|c|c|c|}
\hline \multirow[t]{2}{*}{ Patients } & \multicolumn{3}{|l|}{ Arterial feeders } & \multicolumn{3}{|c|}{ Drainage veins } \\
\hline & DSA & MIP & VR & DSA & MIP & VR \\
\hline $56 / F$ & 2 (AICA, ACS) & 0 & 0 & 1 (SSG) & 1 & 1 \\
\hline $77 / M$ & 1 (ACM) & 1 (ACM) & 1 (ACM) & $1(\mathrm{ST})$ & 0 & 1 \\
\hline $27 / F$ & 3 (ACPI, ACAI, ACS) & 1 (ACPI) & 1 (ACPI) & 4 (SSG, ST) & 0 & 0 \\
\hline $17 / F$ & 2 (ACAl, ACS) & 0 & 0 & 1 (ST) & 1 & 1 \\
\hline $62 / M$ & $2(\mathrm{ACA}, \mathrm{ACM})$ & 2 (ACA, ACM) & 2 (ACA, ACM) & 1 (SSS) & 1 (SSS) & 1 \\
\hline $19 / F$ & 1 (ACP) & $1(\mathrm{ACP})$ & 1 (ACP) & 1 (ST) & 1 & 1 \\
\hline $50 / \mathrm{F}$ & 2 (ACM) & 1 (ACM) & 2 (ACM) & $1(\mathrm{SC})$ & 0 & 0 \\
\hline $34 / \mathrm{M}$ & 1 (ACP) & 1 (ACP) & 1 (ACP) & 1 (SR) & 1 & 1 \\
\hline
\end{tabular}

AICA: Anterior inferior cerebellar artery, ACS: Superior cerebellar artery, ACM: Medial cerebral artery, APIC: Posterior inferior cerebellar artery, ACA: Anterior cerebral artery, ACP: Posterior cerebellar artery, ISS: Inferior sagittal sinus, ST: Transversal sinus, SSS: Superior sagittal sinus, SC: Cavernous sinus, SR: Rectus sinus, SSG: Sigmoid sinus 
TABLE 2. Correlation between DSA and CTA reconstructions determining size of a nidus, sensitivity to diagnose presence of aneurysm, identifying arterial feeders, and drainage veins

\begin{tabular}{lcccc}
\hline Method & Size of a nidus $(\mathrm{mm})$ & Presence of an aneurysm & Arterial feeders & Drainage veins \\
\hline DSA & 12.3 & 1 & 14 & 11 \\
CTA MIP & 12.3 & 1 & 7 & 5 \\
CTA VR & 12.3 & 1 & 8 & 6 \\
CTA MIP+VR & 12.3 & 1 & 8 & 6
\end{tabular}

DSA: Digital subtractions angiography, CTA: Computed tomography angiography, MIP: Intense maximum projection, VR: Volume rendering

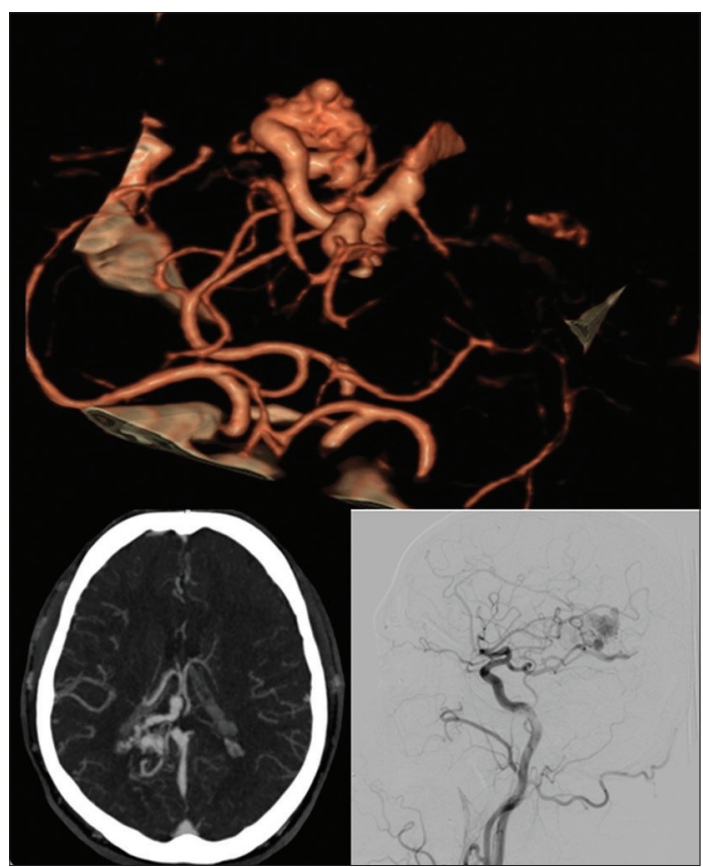

FIGURE 1. Correlation between computed tomography angiography (CTA) volume rendering, CTA intense maximum projection, and DSA findings in a 34-year-old male with arteriovenous malformations.

in our study, only three patients belong to this age group. Four patients were younger age (between 17 and 34 years old), three females and one male. Six AVMs that bled had smaller volume (between 1.5 and $7 \mathrm{~cm}$ ), and only two were large (40 and $31 \mathrm{~cm}$ ). DSA is the method of choice for the diagnosis of AVM, size of nidus, determining the number of arteries which supply blood to AVM, and veins draining the AVM. Yoon et al. (18) have been doing a study on a 16-detector CT scanner. Of the 8 cases with AVM, one has been diagnosed by CTA, and of size $4 \mathrm{~mm}$, CTA gives significantly worse results, then DSA in the diagnosis of the presence and morphology of the AVM. All the blood vessels that supply the AVM could not be visualized as well as all drainage veins.

At the present time, the $3 \mathrm{D}$ reconstruction of CT angiography provides accurate size of AVM, but because of poor temporal resolution CT angiography is not accurate enough to determine the exact localization and size of the AVM nidus, or differentiate in the nidus obliterated or normal blood vessels, such as arteries that bring blood to the AVM or drainage veins, which can be left out by CT angiography, while DSA provides a series of shots at different stages of the passage of contrast through the AVM. Because it is able to dynamically evaluate the contrast flow through the blood vessels so additional stereotactically made DSA is still the standard for secure definition of the AVM nidus, and to plan further treatment, especially because of radiosurgical treatment (gamma knife).

In the study, Hamm et al. (19) proved that the volume of the AVM nidus on 2D DSA is higher than the 3D modalities of DSA CT and MRI. In 19 cases, the volume was smaller in 3D (rotational) DSA; only in 5 cases were able to reduce the volume for radiosurgery from a found volume DSA, while in 5 patients the volume was identical. According to Zipfel et al. (20) are sometimes difficult to define the nidus when it is, due to the rapid flow, covered by arteries and veins involved in the supply and drainage of blood from the AVM.

Most authors believe that the cause of bleeding from the AVM after radiosurgery or radiation covered a smaller volume because the size of nidus was not properly defined or insufficient dose of radiation. (21) Hopefully, in the future, we will develop CT machines of such speed so that they can get the dynamic study and will then be able to replace a large percentage of the DSA. 
Willems et al. (22) evaluated AVM at17 patients by 4D CTA with 320 rows of detectors using dynamic scanning. All 17 AVMs were diagnosed with 4D CTA, with no difference in size compared to DSA. One patient's deep venous drainage was not observed by CTA, arteries which supply AV formation in one patient, in three cases AVM indirect charging through pail collateral were undiagnosed, in two cases expansion of middle cerebral artery was not observed, and deep venous drainage was overlooked.

In our study, there is a significant difference between the findings of DSA and MIP reconstruction of CT angiography in the detection of the arteries that supply blood and venous drainage. MIP reconstruction is displayed only 7 of 14 arterial feeders. Although there are no significant differences between the findings of VR and DSA, only eight arteries which supply the AVM are successfully diagnosed as compared to 14 found by DSA.

Out of 11 drainage veins, MIP reconstruction diagnosed 5 and VR reconstruction diagnosed 6. Our research has shown that for determining the size of the nidus CT angiography finding is sufficient, but the number of arterial feeders and venous drainage findings can only be given based on the findings of DSA.

\section{CONCLUSION}

Spontaneous non-traumatic intracranial hemorrhage is a significant cause of morbidity and mortality worldwide. Intracranial hemorrhage is considered as a medical emergency. CT or MRI examination is essential for the diagnosis of intracranial bleeding. CT is a highly sensitive method for the diagnosis of intracranial bleeding and it is the gold standard.

\section{CONFLICT OF INTERESTS}

Authors declare no conflict o interests.

\section{REFERENCES}

1. Merhemic Z. Netraumatsko intrakranijalno krvarenje. In: Dimitrijevic J, Saradnici I, editors. Urgentna Neurologija. Sarajevo: SaVart; 2006. p. 238-41.

2. Merhemić $Z$, Kadenić $Z$, Sulejmanpašić $G$, Nikšić $M$, Đuherić $A$, Ćatibušić F, et al. Magnetna rezonanca i magnetna angiografija u dijagnostici vaskularnih anomalija dječijeg uzrasta. Med Arh 2000;54(5-6):307-9.

3. Atlas SW. Intracranial hemorrhage. In: Magnetic Resonance Imaging of the Brain and Spine. 3rd ed. Philadelphia, PA: Lippincott, Williams \& Wilkins; 2002. p. 773-832.
4. Brown RD Jr. Wiebers DO, Torner JC, O'Fallon WM. Incidence and prevalence of intracranial vascular malformations in Olmsted county, Minnesota, 1965 to 1992. Neurology 1996;46(4):949-52. https://doi.org/10.1212/ WNL.46.4.949.

5. Friedlander RM. Arteriovenous malformations of the brain. N Engl J Med 2007;356:2704-12. https://doi.org/10.1056/NEJMcp067192.

6. Smith $A B$. Vascular malformations of the brain: Radiologic and pathologic correlation. J Am Osteopath Coll Radiol 2012;1(1):10-22.

7. Hanley M, Zenzen WJ, Brown M, Gaughen JR, Evans AJ. Comparing the accuracy of digital subtraction angiography, CT angiography and MR angiography. Int Neuroradiol 2008;14(2):173-84.https://doi. org/10.1177/159101990801400208.

8. Osborn AG. Intracranial vascular malformations. In: Diagnostic Neuroradiology. St Louis: Mosby; 1994. p. 284-329.

9. Valavanis $A$. The role of angiography in the evaluation of cerebral vascular malformations. Neuroimaging Clin N Am 1996;6(3):679-704.

10. Brown RD Jr., Wiebers DO, Forbes G, O'Fallon WM, Piepgras DG, Marsh WR et al. The natural history of unruptured intracranial arteriovenous malformations. J Neurosurg 1988;68(3):352-7. https://doi.org/10.3171/jns.1988.68.3.0352.

11. Mast H, Mohr JP, Osipov A, Pile-Spellman J, Marshall RS, Lazar RM, et al. 'Steal' is an unestablished mechanism for the clinical presentation of cerebral arteriovenous malformations. Stroke 1995;26(7):1215-20. https://doi. org/10.1161/01.STR.26.7.1215.

12. Pollock BE, Flickinger JC, Lundsford LD, Bissomette DJ, Kondziolka D. Factors that predict the bleeding risk of cerebral arteriovenous malformations. Stroke 1996; 27:1-6. https://doi.org/10.1161/01.STR.27.1.1.

13. Graf CJ, Perret GE, Torner JC. Bleeding from cerebral arteriovenous malformations as part of their natural history. J Neurosurg 1983;58(3):331-7. https://doi.org/10.3171/jns.1983.58.3.0331.

14. Mast H, Young WL, Koennecke HC, Sciacca RR, Osipov A, PileSpellman J, et al. Risk of spontaneous haemorrhage after diagnosis of cerebral arteriovenous malformation. Lancet 1997;350(9084):1065-8. https://doi.org/10.1016/S0140-6736(97)05390-7.

15. Forster DM, Steiner L, Håkanson S. Arteriovenous malformations of the brain. A long-term clinical study. J Neurosurg 1972;37(5):562-70. https:// doi.org/10.3171/jns.1972.37.5.0562.

16. Rinkel GJ, van Gijn J, Wijdicks EF. Subarachnoid hemorrhage without detectable aneurysm. A review of the causes. Stroke 1993;24(9):1403-9. https://doi.org/10.1161/01.STR.24.9.1403.

17. Perry PN. Arteriovenous malformation. In Osborn AG, Salzman KL, Barkovich AJ, editors. Diagnostic imaging: Brain. 2nd ed. Vol. 5. Salt Lake City: Amirsys; 2010. p. 4-7.

18. Yoon DY, Chang SK, Choi CS, Kim WK, Lee JH. Multidetector row CT angiography in spontaneous lobar intracerebral hemorrhage: A prospective comparison with conventional angiography. AJNR Am J Neuroradiol 2009;30(5):962-7. https://doi.org/10.3174/ajnr.A1471.

19. Hamm KD, Klisch J, Surber G, Kleinert G, Eger C, Aschenbach R, et al. Special aspects of diagnostic imaging for radiosurgery of arteriovenous malformations. Neurosurgery 2008;62 5 Suppl: A44-52. https://doi. org/10.1227/01.neu.0000325936.00982.0a.

20. Zipfel GJ, Bradshaw P, Bova FJ, Friedman WA. Do the morphological characteristics of arteriovenous malformations affect the results of radiosurgery? J Neurosurg 2004;101(3):393-401. https://doi.org/10.3171/ jns.2004.101.3.0393.

21. Zabel-du Bois A, Milker-Zabel S, Huber P, Schlegel W, Debus J. Linacbased radiosurgery or hypofractionated stereotactic radiotherapy in the treatment of large cerebral arteriovenous malformations. Int J Radiat Oncol Biol Phys 2006;64(4):1049-54. https://doi.org/10.1016/j. ijrobp.2005.09.021, https://doi.org/10.1016/j.ijrobp.2005.09.024.

22. Willems PW, Taeshineetanakul P, Schenk B, Brouwer PA, Terbrugge KG Krings T, et al. The use of 4D-CTA in the diagnostic work-up of brain arteriovenous malformations. Neuroradiology 2012;54(2):123-31. https://doi. org/10.1007/s00234-011-0864-0. 